E-ISSN 2654-9948

ALGORITMA Journal of Mathematics Education (AJME)

http://journal.uinjkt.ac.id/index.php/algoritma

Vol. 1 No. 2 - Desember 2019, hal. 156-166

\title{
MENGATASI LEARNING OBSTACLE KONSEP TRANSFORMASI GEOMETRI DENGAN DIDACTICAL DESIGN RESEARCH
}

\author{
Ramdani Miftah ${ }^{*}$, Lia Kurniawati, Ticha Putri Solicha \\ Jurusan Pendidikan Matematika, Universitas Islam Negeri Syarif Hidayatullah Jakarta, Banten, Indonesia \\ *Email: ramdani.miftah@uinjkt.ac.id
}

\begin{abstract}
The purpose of this study was to identify learning obstacle precisely on students' epistemological barriers to the concept of geometry transformation. Furthermore, researchers overcome these obstacles by developing mathematical learning concepts in the concept of geometry transformation in high school. This research was conducted at one of the senior high school in Tangerang Selatan. The research method used is Didactical Design Research. This method is carried out in three stages, the analysis of didactic situations before learning (prospective analysis), metapedidactic analysis, and retrospective analysis. Based on the results of the preliminary study, of the 20 students who took the obstacle learning identification test, $82.35 \%$ of the total students experienced epistemological barriers to the concept of geometry transformation. In overcoming the epistemological obstacles students in the concept of geometric transformation requires the design of learning developed based on learning obstacle analysis, repersonalization, and recontextualization so as to produce hypotheses consisting of Hypothetical Learning Trajectory which contains various activities and predictions of student responses and anticipations and produces Student Worksheets. The results show that the didactic design provided can overcome student barriers. It can be seen from the effectiveness of anticipation given during learning that reaches $90 \%$ of the difficulties that arise based on predictions of response and anticipated didactic pedagogical.
\end{abstract}

Keywords : Didactical Design Research (DDR), Didactic Design, Learning Obstacle, Geometry Transformation, Hypothetical Learning Trajectory (HLT).

\begin{abstract}
Abstrak
Penelitian ini bertujuan untuk mengidentifikasi learning obstacle tepatnya pada hambatan epistimologis siswa pada konsep transformasi geometri. Selanjutnya peneliti mengatasi hambatan tersebut dengan cara mengembangkan desain pembelajaran matematika konsep transformasi geometri di SMA. Penelitian ini dilaksanakan di salah satu sekolah menengat atas di Tangerang Selatan. Metode penelitian yang digunakan adalah Didactical Design Research (DDR). Metode ini dilakukan dalam tiga tahapan, yaitu analisis situasi didaktis sebelum pembelajaran (analisis prospektif), analisis metapedadidaktik, dan analisis retrospektif. Berdasarkan hasil studi pendabuluan, dari 20 siswa yang mengikuti tes identifikasi learning obstacle, 82,35\% dari total siswa tersebut mengalami hambatan epistimologis pada konsep transformasi geometri. Dalam mengatasi hambatan epistimologis siswa pada konsep transformasi geometri diperlukan desain pembelajaran yang dikembangkan berdasarkan analisis learning obstacle, repersonalisasi, dan rekontekstualisasi sehingga menghasilkan hipotesis yang terdiri dari Hypothetical Learning Trajectory (HLT) yang berisi berbagai aktivitas dan prediksi respon siswa beserta antisipasinya serta menghasilkan Lembar Kerja Siswa (LKS). Hasil penelitian menunjuk.kan bahwa desain didaktis yang diberikan dapat mengatasi hambatan siswa. Hal tersebut dapat terlihat dari efektifnya antisipasi yang diberikan pada saat pembelajaran yang mencapai 90\% dari kesulitan yang muncul berdasarkan prediksi respon serta antisipasi didaktis pedagogis yang telah dibuat.
\end{abstract}

Kata kunci: Didactical Design Research (DDR), Desain Didaktis, Learning Obstacle, Transformasi Geometri, Hypothetical Learning Trajectory (HLT) 
Format Sitasi: Miftah, R., Kurniawati, L., \& Solicha, T.P. (2019). Mengatasi Learning Obstacle Konsep Transformasi Geometri dengan Didactical Design Research. ALGORITMA Journal of Mathematics Education, 1(2), 156-166.

Permalink/DOI: http://dx.doi.org/10.15408/ajme.v1i2.14076

Naskah Diterima: Nov 2019; Naskah Disetujui: Nov 2019; Naskah Dipublikasikan: Des 2019

\section{PENDAHULUAN}

Matematika merupakan ilmu pengetahuan dasar berupa keterampilan menghitung yang dapat digunakan dalam kehidupan sehari-hari. Matematika pula yang melatih kemampuan seseorang untuk dapat berpikir logis, sistematis, dan kreatif. Suryadi mengungkapkan bahwa pada dasarnya pembelajaran matematika berkaitan dengan guru, siswa, dan matematika (Suryadi, 2010, hlm. 6). Pembelajaran matematika berorientasi pada pola pikir yang terbentuk untuk menjalani kehidupan sehari-hari. Sehingga guru berperan dalam pentransferan ilmu yang mencakup konsep matematika serta penggunaan konsep tersebut dalam menyelesaikan masalah dalam kehidupan sehari-hari. Proses pembelajaran yang seharusnya terjadi yakni interaksi guru dan siswa serta bahan ajar dan juga lingkungan belajar.

Kenyataan yang terjadi, membangun sebuah interaksi yang efektif dalam sebuah proses pembelajaran merupakan hal yang tidak mudah. Kebanyakan siswa masih mengalami kesulitan atau hambatan belajar. Hambatan belajar disebut juga learning obstacle. Brosseau (dalam Sulistiawati, 2015, hlm.137) learning obstacle terbagi menjadi 3 jenis, yaitu: (1) ontogenical learing obstacle yakni kesulitan belajar yang terjadi karena faktor kesiapan mental, (2) didactical learning obstacle merupakan kesulitan belajar yang terjadi karena kesalahan penyajian sehingga menimbulkan miskonsepsi, (3) epistemological learning obstacle adalah kesulitan belajar dikarenakan pemahaman siswa tentang suatu konsep yang kurang lengkap. Kesalahan-kesalahan dalam proses pembelajaran memang disebabkan banyak faktor, bukan hanya dari dalam diri siswa seperti ketidaktahuan siswa namun faktor eksternal seperti yang disebutkan diatas cukup sering dijumpai pada setiap proses pembelajaran. Maka dari itu, peran pendidik dengan peserta didik serta hubungan keduanya terhadap materi pembelajaran dapat menentukan keterlaksanaannya pembelajaran hingga tercapai tujuan pembelajaran yang telah dirumuskan.

Hambatan yang terjadi selama proses pembelajaran transformasi geometri yaitu beberapa siswa dapat melakukan transformasi geometri secara sederhana, namun masih terdapat kesulitan dalam pengerjaan transformasi rotasi dan refleksi untuk bangun yang lebih kompleks (Morris dan Paulsen, 2011, hlm. 132). Siswa juga terhambat dalam menyajikan bukti transformasi geometri 
dalam bentuk aljabar (Naidoo, 2010, hlm. 189-190). Aljabar dapat dijadikan sebagai bentuk umum untuk membuktikan suatu transformasi secara matematis. Transformasi secara kontekstual berupa perpindahan, pencerminan, perputaran, dan penskalaan dapat di generalisasi menggunakan aljabar. Sebagian besar siswa juga mengalami kesulitan pada materi transformasi geometri yang berkaitan dengan arah transformasi (Austin dan Schultz, 1983, h. 98-101). Jenis transformasi berupa rotasi identik dengan penggunaan arah perputaran. Salah satu contohnya yaitu sebuah titik yang di rotasi sejauh $180^{\circ}$ searah dengan perputaran jarum jam. Pada umumnya siswa keliru dalam menentukan arah yang berarti siswa tidak bisa menentukan tanda positif atau negatif hasil transformasi tersebut.

Berdasarkan masalah tersebut, guru berperan dalam mengurangi learning obstacle yang terjadi pada pembelajaran matematika khususnya pada materi transformasi. Salah satu caranya dengan memperhatikan bahan ajar, bahan ajar biasanya hanya berorientasi pada tujuan pembelajaran, tidak memperhatikan hambatan-hambatan yang akan terjadi selama proses pembelajaran. Untuk melihat jenis-jenis learning obstacle pada siswa, mendesain pembelajaran yang sesuai dengan learning obstacle, serta menganalisis respon siswa pada proses pembelajaran, penulis menggunakan didactical design research dalam mengatasi learning obstacle pada konsep transformasi geometri.

\section{TINJAUAN LITERATUR}

\section{Learning Obstacle}

Pada hakikatnya, guru merupakan salah satu profesi yang bertugas sebagai pelayanan masyarakat. Jika seorang dokter berupaya untuk mengatasi keluhan dari setiap pasiennya, maka seorang guru pun tidak berbeda, seorang guru harus mampu mengatasi keluhan dari siswa. Keluhan tersebut diantaranya berupa kesulitan-kesulitan yang dihadapi selama proses pembelajaran. Kesulitan dan hambatan belajar yang dihadapi siswa sering disebut juga sebagai learning obstacle.

Karakteristik matematika dengan objek yang abstrak, konsep dan prinsipnya berjenjang serta pemecahan masalah yang prosedural menjadi salah satu penyebab munculnya hambatan belajar. Menurut Brousseau, terdapat tiga jenis faktor terjadinya hambatan belajar (learning obstacle) (Brousseau, 1997, hlm. 86), yaitu:

1. Hambatan ontogenis (ontogenic obstacle)

Hambatan ontogenik merupakan hambatan belajar berdasarkan perkembangan kesiapan mental siswa dalam proses pembelajaran.

2. Hambatan didaktis (didactical obstacle)

Hambatan didaktis merupakan hambatan belajar akibat dari kesalahan pemilihan bahan ajar maupun kesalahan penyampaian bahan ajar yang dilakukan oleh guru. 
3. Hambatan epistemologis (epistemological obstacle)

Hambatan epistemologis merupakan hambatan belajar yang disebabkan oleh keterbatasan siswa untuk memahami dan mengaplikasikan konsep matematika itu sendiri. Hambatan ini perlu diperhatikan karena pada dasarnya konsep matematika berkaitan satu sama lainnya. Dengan adanya keterkaitan konsep ini berarti pemahaman suatu konsep akan berpengaruh pada pemahaman konsep yang berkaitan lainnya.

Hambatan belajar yang menjadi fokus pada penelitian ini yaitu hambatan epistemologis. Hambatan epistemologis berkaitan erat dengan objek dengan kajian abstrak seperti matematika. Objek matematika meliputi fakta, konsep, prinsip dan operasi. Kemampuan siswa terhadap objek matematika tersebut dapat diketahui dengan cara diberikannya persoalan-persoalan matematika yang harus diselesaikan.

Hambatan epistemologis dapat diidentifikasi dari hasil penyelesaian persoalan matematika yang dilakukan oleh siswa. Jika hasil tersebut menunjukan adanya hambatan epistemologis, maka perlu disusun analisis kesulitan siswa terhadap materi yang dipersoalkan. Dengan demikian, untuk mengidentifikasi hambatan belajar siswa dalam mempelajari transformasi geometri, maka perlu dirancang tes khusus dengan materi transformasi geometri.

\section{Metapedadidaktis}

Hubungan dalam pembelajaran diilustrasikan sebagai segitiga didaktik yang menggambarkan hubungan didaktis (HD) terjalin antara siswa dengan materi, hubungan pedagogis (HP) terjalin antara guru dengan siswa, serta hubungan antara guru dengan materi disebut sebagai antisipasi didaktis pedagogis (ADP) (Suryadi, 2008, hlm 9). Hubungan guru-siswa-materi digambarkan oleh Kansanen yang dimodifikasi sebagai berikut:

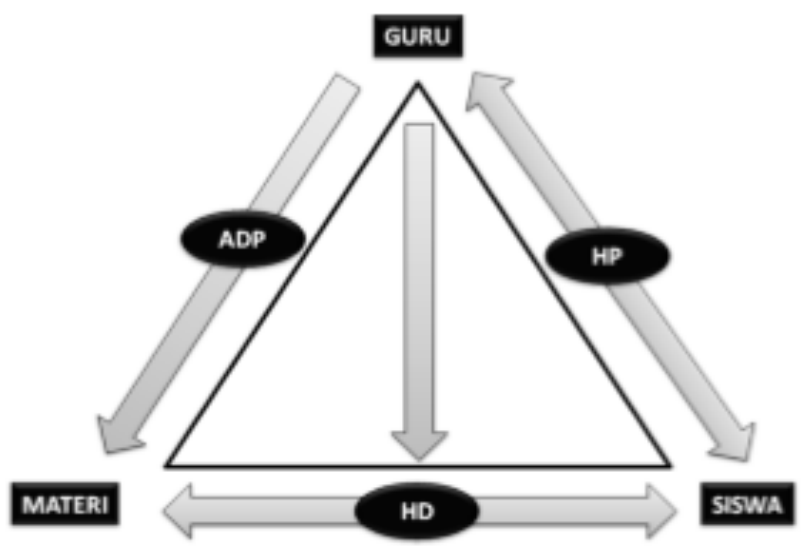

Gambar 1. Segitiga Metapedidaktis 
Peran guru dalam konteks segitiga didaktis ini cukup penting, diantaranya yaitu menciptakan suatu situasi didaktis (didactical situation) sehingga terjadi proses belajar dalam diri siswa (learning situation). Hal ini berarti bahwa seorang guru perlu memiliki pengetahuan yang mampu menciptakan situasi didaktis yang dapat mendorong proses belajar siswa secara optimal. Hal ini berarti, seorang guru perlu memiliki kemampuan untuk menciptakan relasi didaktis (didactical relation) antara siswa dan materi ajar sehingga tercipta suatu situasi didaktis ideal bagi siswa (Suryadi, 2013, hlm. 5). Menurut Suryadi, metapedadidaktis merupakan kemampuan seorang guru untuk: (1) memandang komponen-komponen segitiga didaktis yang dimodifikasi yaitu ADP, HD, dan HP sebagai suatu kesatuan yang utuh, (2) mengembangkan tindakan sehingga tercipta situasi didaktis dan pedagogis yang sesuai kebutuhan siswa, (3) mengidentifikasi serta menganalisis berbagai respon siswa sebagai akibat tindakan didaktis maupun pedagogis yang dilakukan, (4) melakukan tindakan didaktis dan pedagogis lanjutan berdasarkan hasil analisis respon siswa menuju pencapaian target pembelajaran (Suryadi, 2013, hlm. 9).

Metapedadidaktis meliputi tiga komponen yang terintegrasi yaitu kesatuan, fleksibilitas, dan koherensi (Suryadi, 2013, hlm. 9). Komponen kesatuan berkenaan dengan kemampuan guru untuk memandang segitiga didaktis yang dimodifikasi sebagai sesuatu yang utuh dan saling berkaitan erat satu sama lainnya. Komponen yang kedua adalah fleksibilitas, beragam respon siswa serta antisipasinya hanyalah rencana yang belum tentu menjadi kenyataan. Dalam proses pembelajaran, guru harus mampu memodifikasi hal-hal tersebut sesuai dengan kenyataan yang terjadi. Dengan demikian antisipasi yang telah direncanakan perlu disesuaikan dengan kondisi didaktis dan pedagogis yang terjadi. Komponen yang ketiga adalah koherensi. Situasi didaktis yang diciptakan sejak awal pembelajaran tidak akan bersifat tetap, karena adanya respon siswa yang terjadi saat pembelajaran. Akibatnya akan muncul situasi didaktis dan situasi pedagogis baru. Hal tersebut mengakibatkan terjadinya perubahan-perubahan situasi saat proses pembelajaran, maka guru perlu memperhatikan koherensi atau hubungan logis dari tiap situasi sehingga tercipta proses pembelajaran yang optimal.

\section{Teori Belajar}

1. Teori Piaget

Piaget mengungkapkan bahwa pengalaman fisik serta interaksi dengan lingkungan merupakan hal penting terjadinya perkembangan (Suprihatiningrum, 2013, hlm.24). Perkembangan kognitif sebagian besar ditentukan oleh adaptasi anak dengan lingkungan. Proses adaptasi yang dilakukan seorang anak mencakup kegiatan asimilasi dan akomodasi (Suprihatiningrum, 2013, hlm.24). Asimilasi merupakan kegiatan menyaring atau mendapatkan 
pengalaman-pengalaman baru sebagai sumber utama struktur pemahamannya. Sedangkan kegiatan akomodasi merupakan proses menstruktur kembali pengalaman-pengalaman baru dengan cara memodifikasi yakni mengembangkan serta melengkapi struktur pemahaman menjadi pemahaman yang benar dan baru.

2. Teori Ausubel

Menurut Ausubel, belajar bermakna merupakan suatu proses dikaitkannya informasi baru pada konsep-konsep yang relevan yang terdapat dalam struktur kognitif seseorang (Dahar, 2006, hlm.95). Pemerolehan informasi merupakan tujuan pembelajaran yang penting, dalam hal ini guru berperan mengorganisasikan apa yang perlu dipelajari oleh siswa. Pembelajaran yang efektif tidak hanya dengan cara belajar penemuan. Namun siswa juga dapat belajar dengan penerimaan yang bermakna, yakni dengan mengaitkan pengetahuan baru yang didapat dengan struktur kognitif yang telah dimiliki.

Dalam hal ini, kebermaknaan pembelajaran didapat ketika siswa memperoleh masalah berupa soal, maka siswa akan mengaitkan dengan informasi yang sudah didapat sebelumnya kemudian barulah ia bisa menyelesaikan masalah tersebut. Contohnya dalam pembelajaran matematika pada materi transformasi. Ketika siswa dihadapkan pada masalah berupa soal transformasi, langkah pertama yang harus dilakukan adalah memahami soal termasuk kedalam jenis transformasi translasi, refleksi, rotasi atau dilatasi. Setelah itu, siswa akan menyelesaikan menggunakan rumus yang mengandung fungsi dan persamaan matriks sebagai bukti aljabar penyelesaian transformasi. Dengan demikian, siswa akan membentuk pengetahuannya sesuai dengan macam macam masalah yang telah diselesaikan.

\section{METODE}

Pada penelitian ini, penulis menggunakan penelitian kualitatif berupa Didactical Design Research (DDR). Penelitian ini dilakukan untuk mengetahui desain didaktis yang sesuai untuk mengatasi kesulitan belajar pada materi transformasi geometri.

Secara umum, penelitian desain didaktis terdiri atas tiga tahapan: 1) analisis situasi didaktis sebelum pembelajaran (analisis prospektif) yang wujudnya berupa desain didaktis hipotesis dan antisipasi didaktis pedagogis (ADP); 2) analisis situasi didaktis-pedagogis atau analisis metapedadidaktis; dan 3) analisis retrospektif yang mengaitkan analisis situasi didaktis hipotetis dengan analisis situasi metapedadidaktis (Suratno, 2016, hlm. 7).

Penelitian ini dilakukan di MA Khazanah Kebajikan Kota Tangerang Selatan pada bulan Maret 2019. Penelitian ini dilaksanakan kepada 20 siswa di kelas XI MIA semester II tahun ajaran 2018/2019. Sedangkan subjek instrumen learning obstacle yaitu 20 siswa kelas XII MIA dan IIS yang 
telah mempelajari maeri transformasi geometri. Teknik pengumpulan data yang digunakan yaitu studi literatur dan studi lapangan. Secara khusus, pengumpulan data yang akan dilakukan dalam penelitian ini yaitu dengan teknik triangulasi yang terdiri dari wawancara, observasi, dan dokumentasi.

Dalam penelitian desain didaktis dilakukan tiga tahapan penelitian, yaitu pertama analisis situasi didaktis sebelum pembelajaran, tahap ini berlangsung layaknya pendahuluan dalam penelitian. Pada tahap ini akan dilakukan TKR awal, setelah itu dilakukan wawancara sebagai pendukung hasil TKR untuk menentukan learning obstacle yang muncul pada konsep transformasi geometri. Kemudian akan dilakukan penyusunan desain didaktis konsep transformasi geometri, bersama dengan itu juga dilakukan penyusunan prediksi respon siswa yang mungkin muncul pada saat pengimplementasi desain didaktis. Tahap kedua yaitu analisis metapedadidaktis, yakni tahap saat desain didaktis diimplementasikan dan dilakukan analisis respon siswa terhadap desain didaktis yang berlangsung dalam pembelajaran. Tahap terakhir yaitu analisis retrospektif, yakni analisis hasil implementasi dari desain didaktis. Pada tahap ini dilakukan analisis terhadap hasil implementasi desain didaktis. Kemudian mengaitkan hasil implementasi situasi didaktis hipotesis dengan hasil analisis metapedadidaktis. Setelah itu peneliti akan menyusun desain didaktis revisi.

\section{HASIL DAN PEMBAHASAN}

\section{Identifikasi learning obstacle}

Identifikasi learning obstacle pada penelitian ini dibagi menjadi dua jenis, yaitu Jenis 1 : learning obstacle terkait dengan materi prasyarat berupa operasi persamaan aljabar serta menyelesaikan persamaan pada aljabar, dan operasi perkalian pada matriks. Jenis 2: learning obstacle terkait dengan konsep transformasi geometri yakni (1) translasi titik yang masih terdapat variabel, (2) konsep refleksi serta penerapannya pada persamaan lingkaran, (3) konsep rotasi dengan titik pusat $\overline{P(a, b)}$ serta penggunaan sudut yang searah dan berlawanan arah jarum jam, (4) konsep dilatasi dengan titik pusat $\overline{P(a, b)}$.

\section{Analisis metapedadidaktis}

Implementasi desain didaktis dilakukan di MA Khazanah Kebajikan Pondok Cabe. Desain didaktis ini diberikan pada kelas XI MIA dengan jumlah siswa 12 orang. Hasil analisis terhadap implementasi desain didaktis secara lengkap di sajikan pada tabel berikut. 
Tabel 1. Analisis Metapedadidaktis

\begin{tabular}{|c|c|c|}
\hline $\begin{array}{l}\text { Desain } \\
\text { didaktis }\end{array}$ & Situasi didaktis & Hasil implementasi \\
\hline \multirow{2}{*}{$\begin{array}{l}\text { Desain didaktis } \\
\text { konsep translasi }\end{array}$} & Situasi didaktis 1 & $\begin{array}{l}\text { Terdapat antisipasi yang diprediksi sebelumnya } \\
\text { tidak mampu mengatasi kesulitan, sehingga } \\
\text { diberikan antisipasi baru. }\end{array}$ \\
\hline & Situasi didaktis 2 & $\begin{array}{l}\text { Terdapat antisipasi yang diprediksi sebelumnya } \\
\text { mampu mengatasi kesulitan, sehingga tidak } \\
\text { diperlukan antisipasi baru. }\end{array}$ \\
\hline \multirow{2}{*}{$\begin{array}{l}\text { Desain didaktis } \\
\text { konsep refleksi }\end{array}$} & Situasi didaktis 1 & $\begin{array}{l}\text { Terdapat antisipasi yang diprediksi sebelumnya } \\
\text { tidak mampu mengatasi kesulitan, sehingga } \\
\text { diberikan antisipasi baru. }\end{array}$ \\
\hline & Situasi didaktis 2 & $\begin{array}{l}\text { Terdapat antisipasi yang diprediksi sebelumnya } \\
\text { mampu mengatasi kesulitan, sehingga tidak } \\
\text { diperlukan antisipasi baru. }\end{array}$ \\
\hline \multirow{2}{*}{$\begin{array}{l}\text { Desain didaktis } \\
\text { konsep rotasi }\end{array}$} & Situasi didaktis 1 & $\begin{array}{l}\text { Terdapat antisipasi yang diprediksi sebelumnya } \\
\text { tidak mampu mengatasi kesulitan, sehingga } \\
\text { diberikan antisipasi baru. }\end{array}$ \\
\hline & Situasi didaktis 2 & $\begin{array}{l}\text { Terdapat antisipasi yang diprediksi sebelumnya } \\
\text { mampu mengatasi kesulitan, sehingga tidak } \\
\text { diperlukan antisipasi baru. }\end{array}$ \\
\hline \multirow{2}{*}{$\begin{array}{l}\text { Desain didaktis } \\
\text { konsep dilatasi }\end{array}$} & Situasi didaktis 1 & $\begin{array}{l}\text { Terdapat antisipasi yang diprediksi sebelumnya } \\
\text { tidak mampu mengatasi kesulitan, sehingga } \\
\text { diberikan antisipasi baru. }\end{array}$ \\
\hline & Situasi didaktis 2 & $\begin{array}{l}\text { Terdapat antisipasi yang diprediksi sebelumnya } \\
\text { mampu mengatasi kesulitan, sehingga tidak } \\
\text { diperlukan antisipasi baru. }\end{array}$ \\
\hline
\end{tabular}

Respon siswa pada penerapan desain didaktis konsep transformasi geometri secara keseluruhan berdasarkan analisis pada situasi 1 dan 2 pada setiap desain didaktis terdapat kemungkinan kesulitan yang muncul sebesar 62,5\% dari kemungkinan kesulitan yang telah diprediksikan sebelumnya. Dari 62,5\% kemungkinan kesulitan yang muncul sebesar 90\% efektif dalam mengantisipasi kemungkinan kesulitan yang ada. Adapun kesulitan yang tak terprediksi atau kesulitan baru yang muncul sejumlah 5 pada desain didaktis yang telah dirancang. Hal ini dapat disimpulkan bahwa desain didiaktis konsep transformasi geometri mampu mengurangi learning obstacle.

\section{Analisis Retrospektif}

Analisis retrospektif, yaitu analisis terhadap hasil implementasi desain didaktis kemudian mengaitkan hasil implementasi situasi didaktis hipotesis dengan hasil analisis metapedadidaktis. Berdasarkan analisis metapedadidaktis yang telah dilakukan, maka analisis retrospektif di deskripsikan pada tabel berikut. 
Tabel 2. Analisis Retrospektif

\begin{tabular}{|c|c|c|}
\hline $\begin{array}{c}\text { Desain } \\
\text { didaktis }\end{array}$ & Situasi didaktis & Hasil revisi \\
\hline \multirow[t]{2}{*}{$\begin{array}{l}\text { Desain didaktis } \\
\text { konsep translasi }\end{array}$} & Situasi didaktis 1 & $\begin{array}{l}\text { Perluasan prediksi respon siswa berupa pertanyaan } \\
\text { seputar konsep translasi serta guru memberikan } \\
\text { arahan yang lebih spesifik pada lks agar siswa } \\
\text { menuliskan pertanyaan seputar konsep translasi yang } \\
\text { ingin diketahui. }\end{array}$ \\
\hline & Situasi didaktis 2 & Tidak terdapat perubahan \\
\hline \multirow[t]{2}{*}{$\begin{array}{l}\text { Desain didaktis } \\
\text { konsep refleksi }\end{array}$} & Situasi didaktis 1 & $\begin{array}{l}\text { Perluasan prediksi respon siswa berupa pertanyaan } \\
\text { seputar konsep refleksi serta guru memberikan arahan } \\
\text { yang lebih spesifik pada lks agar siswa menuliskan } \\
\text { pertanyaan seputar konsep refleksi yang ingin } \\
\text { diketahui. }\end{array}$ \\
\hline & Situasi didaktis 2 & Tidak terdapat perubahan \\
\hline \multirow[t]{2}{*}{$\begin{array}{l}\text { Desain didaktis } \\
\text { konsep rotasi }\end{array}$} & Situasi didaktis 1 & $\begin{array}{l}\text { Perluasan prediksi respon siswa berupa pertanyaan } \\
\text { seputar konsep rotasi serta guru memberikan arahan } \\
\text { yang lebih spesifik pada lks agar siswa menuliskan } \\
\text { pertanyaan seputar konsep rotasi yang ingin diketahui. } \\
\text { Penambahan penugasan yaitu siswa diminta mencari } \\
\text { sudut rotasi yang digunakan. } \\
\text { Perluasan prediksi respon siswa berupa penambahan } \\
\text { keterangan sudut rotasi yang digunakan pada soal. } \\
\text { Perluasan kemungkinan kesulitan serta antisipasi } \\
\text { didaktis pedagogis. }\end{array}$ \\
\hline & Situasi didaktis 2 & Tidak terdapat perubahan \\
\hline \multirow[t]{2}{*}{$\begin{array}{l}\text { Desain didaktis } \\
\text { konsep dilatasi }\end{array}$} & Situasi didaktis 1 & $\begin{array}{l}\text { Perluasan prediksi respon siswa berupa pertanyaan } \\
\text { seputar konsep dilatasi serta guru memberikan arahan } \\
\text { yang lebih spesifik pada lks agar siswa menuliskan } \\
\text { pertanyaan seputar konsep dilatasi yang ingin } \\
\text { diketahui. }\end{array}$ \\
\hline & Situasi didaktis 2 & Tidak terdapat perubahan \\
\hline
\end{tabular}

\section{KESIMPULAN DAN REKOMENDASI}

Identifikasi learning obstacle pada penelitian ini dibagi menjadi dua jenis, yaitu Jenis 1 : learning obstacle terkait dengan materi prasyarat. Jenis 2: learning obstacle terkait dengan konsep transformasi geometri. Desain didaktis awal dikembangkan berdasarkan hasil analisis learning obstacle serta antisipasi didaktis pedagogis berdasar kemungkinan kesulitan yang akan muncul. Desain didaktis konsep transformasi geometri terdiri dari empat kegiatan pembelajaran yaitu (1) desain didaktis konsep translasi, (2) desain didaktis konsep refleksi, (3) desain didaktis konsep rotasi, dan (4) desain didaktis konsep dilatasi.

Respon siswa pada penerapan desain didaktis konsep transformasi geometri secara keseluruhan berdasarkan analisis pada situasi 1 dan 2 pada setiap desain didaktis terdapat kemungkinan kesulitan yang telah diprediksikan sebelumnya. Dari kemungkinan kesulitan yang muncul, antisipasi desain didaktis pedagogis efektif dalam mengantisipasi kemungkinan kesulitan yang ada. Hal ini dapat disimpulkan bahwa desain didiaktis konsep transformasi geometri mampu mengurangi learning obstacle. Desain didaktis revisi yang dilakukan pada desain didaktis awal yakni berupa penambahan penugasan, perluasan prediksi respon dan antisipasi didaktis pedagogis. 
Berdasarkan hasil penelitian dan kesimpulan yang diperoleh, peneliti memberikan beberapa saran terkait desain didaktis pada pembelajaran konsep transformasi geometri, yaitu : (1) Bagi guru dapat menjadikan desain didaktis konsep transformasi geometri sebagai alternatif desain yang dapat diimplementasikan pada pembelajaran transformasi geometri, agar mendapatkan hasil yang lebih optimal dalam pembelajaran transformasi geometri. (2) Bagi sekolah dengan adanya penelitian ini dapat menjadi acuan dalam meningkatkan dan memperbaiki kualitas pembelajaran di sekolah, serta dapat menyarankan guru mata pelajaran matematika untuk menggunakan desain didaktis konsep transformasi geometri sebagai alternatif desain pembelajaran. (3) Bagi peneliti selanjutnya disarankan sebelum membuat desain didaktis, sebaiknya dilakukan uji learning obstacle yang didahului dengan proses pengkajian materi transformasi geometri berdasarkan buku pegangan siswa serta melakukan observasi dan wawancara untuk mengidentifikasi kesulitan awal yang akan dialami oleh siswa. Desain didaktis konsep transformasi geometri yang disusun dapat terus dikembangkan dengan perbaikan dan penelitian, baik dari sisi kesulitan siswa, bahan ajar, maupun perluasan prediksi respon siswa untuk memperoleh desain pembelajaran yang lebih optimal.

\section{REFERENSI}

Adjie, Nahrowie dan R. Deti Rostika. (2006). Konsep dasar matematika. Bandung: UPI Press.

Schultz, K. A. and Austin, J. D. (1983). Directional effect in transformation tasks. Journal for Research in Mathematics Education, 14(2), 95-101. https://doi.org/10.2307/748577

Brousseau, G. 1997. Theory of didactical situation in mathematic. Drodrecht: Kluwer Academic Publisher.

Dahar, R. W. (2006). Teori-teori belajar dan pembelajaran. Jakarta: Erlangga.

Kementerian Pendidikan dan Kebudayaan Republik Indonesia (Kemdikbud). (2012). Hasil UN berdasarkan penguasaan materi ujian nasional, [Online] Tersedia di: http://hasilun.puspendik.kemdikbud.go.id, diakses 20 Juli 2019.

Lidnillah, D. A. M. (2012). .Educational design research: a theoritical framework for action, [Online] Tersedia di: http:// file.upi.edu. diakses 14 Agustus 2018.

Naidoo, J. (2010). Strategies used by grade 12 mathematics learners in transformation geometry.

Proceeding of Southern African Assosiation for Research in Mathematics, Science, and Technology Education, 2.

Negoro, S. T. \& Harahap, B. (2003). Ensiklopedia matematika. Bogor: PT. Ghalia Indonesia.

Paulsen, R. \& M, T. (2011). Using tracing paper to teach transformation geometry. Proceeding of Association for Mathematics Education of South Africa (AMESA), 2.

Sulistiawati., Suryadi, D., \& Fatimah, S. (2015). Desain didaktis penalaran matematis untuk mengatasi kesulitan belajar siswa smp pada luas dan volume limas. Kreano Jurnal Matematika Kreatif-Inovatif, 6(2), 135-146. https://doi.org/10.15294/kreano.v6i2.4833

Suprihatiningrum, J. (2013). Strategi pembelajaran: teori \& aplikasi. Jogjakarta: Ar-Ruzz Media. 
Suratno, T. (2016). Didaktik dan didactical design research dalam Didi Suryadi, dkk. Monograf Didaktical Design Research. Bandung: Rizqi Press.

Suryadi, D. (2013). Didactical design research (DDR) dalam pengembangan pembelajaran. Prosiding Seminar STKIP Siliwangi. Bandung: STKIP SIliwangi.

Suryadi, D. (2010). Menciptakan proses belajar aktif: kajian dari sudut pandang teori belajar dan didaktik. Makalah Seminar UNP. Padang: Universitas Negeri Padang.

Suryadi, Didi. (2008). Metapedadidaktis dalam Pembelajaran Matematika: Suatu Strategi Pengembangan Diri Menuju Guru Matematika Profesional. Pidato Pengukuhan. Bandung: UPI. 